\title{
Immunohistochemical Demonstration of Peptidergic Nerve Fibers Associated with the Central Lacteal Lymphatics in the Duodenal Villi of Dogs
}

\author{
Sanae ICHIKAWA ${ }^{1}$, Masami Shiozawa ${ }^{1}$, Toshihiko Iwanaga ${ }^{2}$ and Shigeo UChino ${ }^{1}$ \\ Department of Anatomy ${ }^{1}$, Tokyo Medical College, Tokyo; and Department of Anatomy², Niigata University School of Medicine, \\ Niigata, Japan \\ Received February 28, 1991
}

\begin{abstract}
Summary. Immunohistochemical demonstration was made of the peptidergic nerves distributed in the central lacteal lymphatics of the canine duodenal villi. The central lacteal-associating nerve fibers were predominantly immunoreactive for both substance $P$ (SP) and calcitonin gene-related peptide (CGRP). Observation of doubly immunostained sections evidenced that both peptides were located in one and the same nerve fibers. The SP/CGRP-immunoreactive fibers were concentrated in the intermediate portion of the villus height. Ultrastructurally, the SP/CGRP-immunoreactive nerve fibers ran closely beneath the endothelial cells of the lacteal, some of them penetrating into the cytoplasm with knob-like swellings. The immunoreactive products were localized to large-cored vesicles in the sub- and intraendothelial nerves.

The occurrence of SP and CGRP in the nerve fibers distributed in the central lacteals which lack smooth muscles implies that these nerves may be sensory in nature. A mechanoreceptive function of the nerves is proposed on the basis of their peculiar knob-like projection into the lacteal endothelium.
\end{abstract}

The central lacteal lymphatics in the intestinal villi display a lymphatic system with a highly active lymph flow. The lymph flow is considered to be caused by the rhythmical contraction of smooth muscle cells which ran longitudinally in the core of the intestinal villi (CAMPBELl and HeATH, 1973; Hall et al., 1965; MCHALE et al., 1980). The activity of smooth muscle cells should be controlled by autonomic neurons which are conspicuously numerous in the lamina propria of the villi (Bulbring et al., 1970; MCHALE et al., 1980).

No specialized relationship had been recorded between the nerve elements and the central lacteal lymphatics until our recent demonstration under the electron microscope of an intimate relationship of the nerve terminals with the endothelium of central lacteals in the duodenal villi of the dog (ICHIKAWA et al., 1989, 1990). These nerve terminals contained numerous large-cored vesicles which probably corresponded to the storage sites of peptidergic transmitters (HöKFELT et al., 1980). Some of the nerve fibers to the central lacteals were found to penetrate into the endothelial cells. We felt that the rich innervation of the central lacteals was an enigmatic image because these lymphatic vessels were lacking in those smooth muscles regulated by nerves.

The present study aims to identify the types of nerves distributed in the central lacteal lymphatics in the canine duodenum. Since peptidergic neurons are predominant in the intestinal mucosa, their identification was performed by immunohistochemistry using antisera against various neuropeptides at light and electron microscopic levels.

\section{MATERIALS AND METHODS}

Six adult mongrel dogs (7-10 kg in body weight) were used in this study. The animals were deeply anesthetized with an intravenous injection of sodium pentobarbiturate $(15 \mathrm{mg} / \mathrm{kg}$ body weight). In order to wash out the blood, the vascular bed was perfused with $500 \mathrm{ml}$ of Ringer's solution through a catheter inserted into the thoracic aorta. The dogs were then perfused through the thoracic aorta with $4 \%$ paraformaldehyde in $0.1 \mathrm{M}$ phosphate buffer, $\mathrm{pH}$ 7.4. Tissues were removed from the duodenal bulb, dissected and immersed in the same fixative for $6 \mathrm{~h}$ at room temperature. After fixation, the specimens were immer- 
sed for 2 days in 30\% sucrose solution. They were rapidly frozen in liquid nitrogen and cut at a $15 \mu \mathrm{m}$ thickness by a cryostat.

The cryostat sections were pretreated with a normal pig serum diluted at 1:20 for $30 \mathrm{~min}$ and incubated overnight at room temperature with polyclonal antisera raised against each of the following peptides; 1) substance $\mathrm{P}(\mathrm{SP})$ (at a dilution of $1: 2,000 ; \mathrm{R} 2402$, Dr. N. YANAIHARA, Japan); 2) rat calcitonin gene-related peptide (CGRP) $(1: 4,000$; RPN. 1842, Amersham, England); 3) vasoactive intestinal polypeptide (VIP) (1:2,000; R 502; YANAIHARA et al., 1977); 4) gastrinreleasing peptide (GRP) $(1: 3,000 ; \mathrm{R} 6902$, YANAIHARA et al., 1981); 5) neuropeptide Y (NPY) $(1: 4,000$; RPN. 1702, Amersham, England); 6) Met-enkephalin-ArgGly-Leu (Met-EK-8) (1:3,000; R 0171; NiheI and IwANAGA, 1985); and 7) galanin (1:2,000; R 0672, Dr. $\mathrm{N}$. YANAIHARA, Japan). The sites of the antigenantibody reaction were revealed by the $\mathrm{ABC}$ (avidinbiotin complex) method using a Biotin-Strepto-Avidin Immunostaining Kit (BioGenex Lab, Doublin, U.S.A.).

\section{Double immunofluorescence staining}

The CGRP antiserum used for double staining was the same as that used in the $\mathrm{ABC}$ method, while for the SP antibody, the rat monoclonal antibody ( $\mathrm{NC1} /$ 34-HL, Sera-Lab, England) was employed. Cryostat sections were first incubated with the rabbit CGRP antiserum diluted at 1:400 for $2 \mathrm{~h}$, followed by fluorescein isothiocyanate (FITC)-coupled porcine antirabbit IgG (Dakopatts, Denmark) diluted at 1:20. Immunostained sections were thoroughly washed in a phosphate-buffered saline and then incubated with the rat monoclonal antibody against SP diluted at 1 : 100 for $2 \mathrm{~h}$. The site of antigen-antibody reaction was revealed by rhodamine-labelled goat anti-rat IgG (Cappel, U.S.A) diluted at 1:20.

Double-stained sections were observed and photographed under a Leiz Ortholux equipped with a fluorescence vertical illuminator (Ploemopak 2.2). The specificity of the immunostaining was confirmed as follows: for the SP antibody, when a rat normal serum or antigen-absorbed antibody was substituted, only FITC-fluorescent nerve fibers were recognized. On the other hand, when a rabbit normal serum or antigen-absorbed antiserum was used instead of the CGRP antiserum, only rhodamine-fluorescent nerve fibers were present.
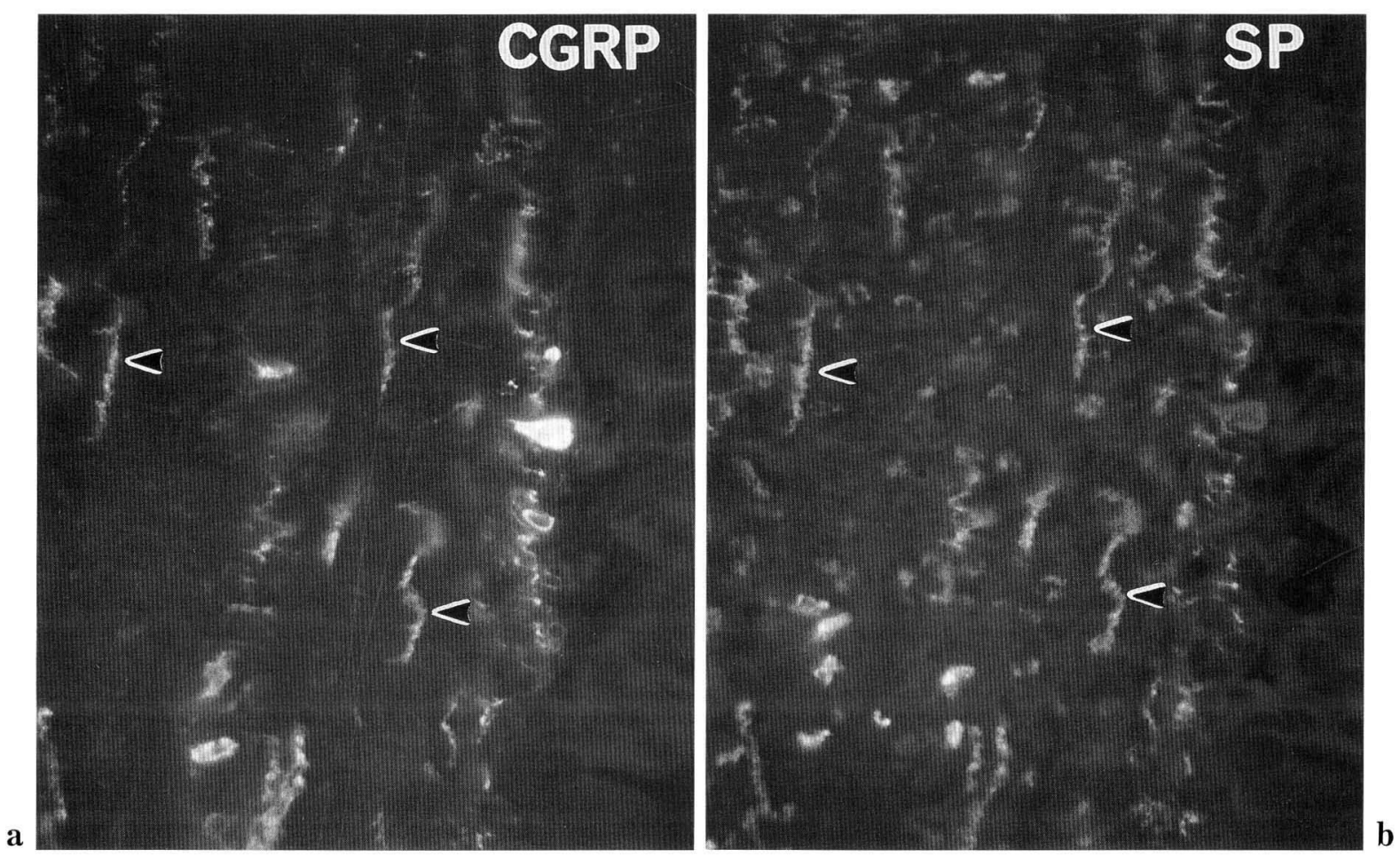

Fig. 1. A single section from the dog duodenum is double-stained by use of antibodies against CGRP (a) and SP (b). Identical nerve fibers running perpendicularly in a villus show both FITC fluorescence for CGRP and rhodamine fluorescence for SP. $\times 180$ 
For electron microscopic observation, some immunostained sections were post-fixed in 1\% OsO4 for $30 \mathrm{~min}$ and embedded in Araldite according to routine procedures. Ultrathin sections were stained with uranyl acetate and observed by a JEOL 100 CXII electron microscope.

\section{RESULTS}

The duodenal villi, remarkably long $(600-700 \mu \mathrm{m})$ in dogs, were divided along their long axes into the following three portions: the proximal, intermediate and distal portions. These three portions differed from each other in their distributions of nerves as well as the morphology of blood vessels and central lacteals (cf. IcHIKAWA et al., 1990).
The immunohistochemical staining of neuropeptides indicated that nerve fibers immunoreactive for SP, CGRP, VIP were numerous in the villi, while GRP, NPY, Met-EK-8 and galanin-positive fibers were rare.

The SP and CGRP-immunoreactive nerve fibers appeared to display similar localizations and running patterns, suggesting that SP and CGRP were colocalized in the same nerve fibers. This idea was confirmed by means of double immunofluorescence staining using the rabbit antiserum against CGRP (FITC) and that against SP (rhodamine) (Fig. 1a, b).

The VIP-immunoreactive fibers were closely related to smooth muscles and subepithelial vascular beds, and only occasionally appeared around the central lacteals. The present paper will therefore focus on the distribution and ultrastructure of the

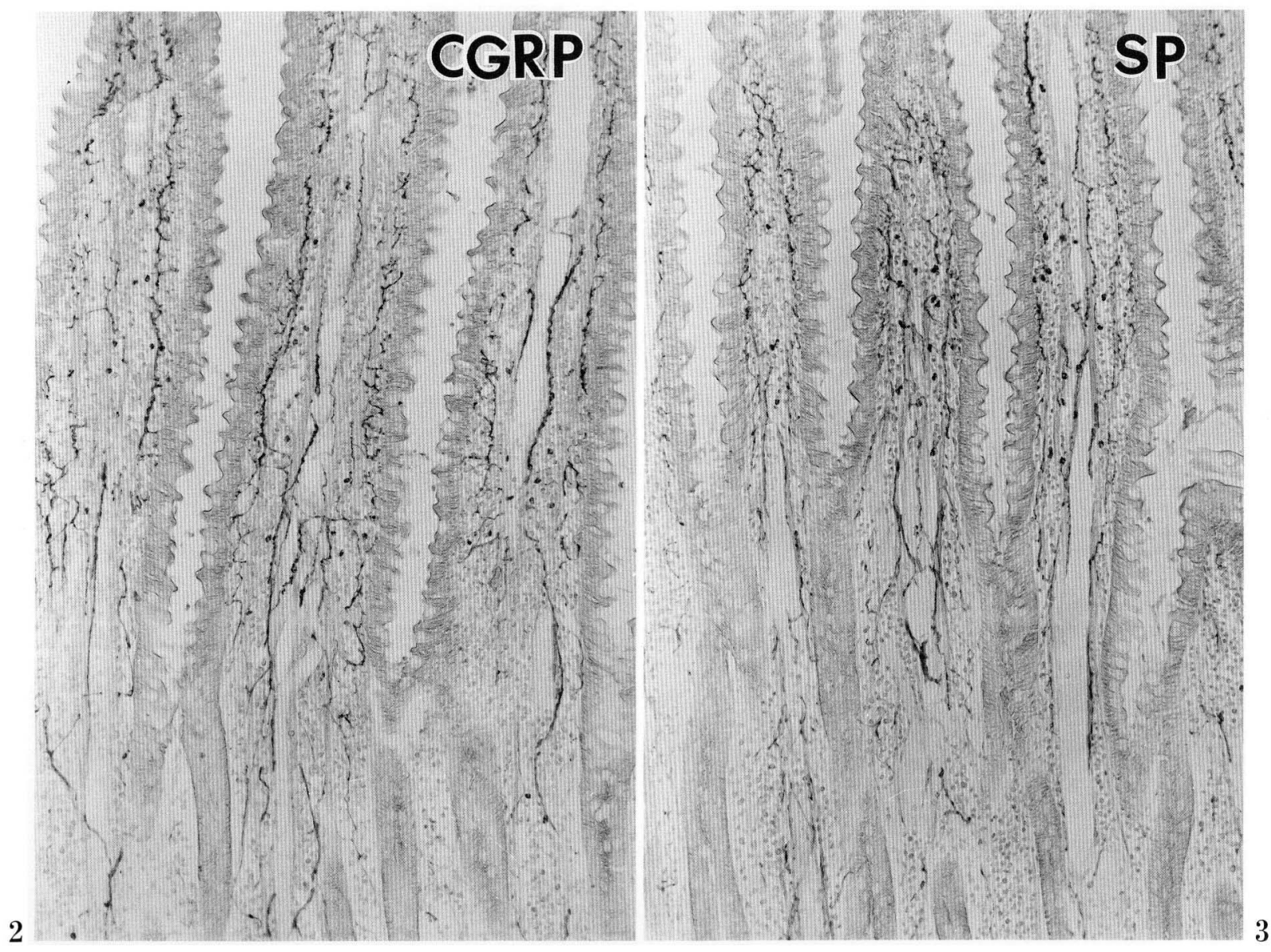

Figs. 2 and 3. CGRP- (Fig. 2) and SP-immunoreactive nerves (Fig. 3) in the duodenal villi of dogs. ABC immunostaining. Numerous immunoreactive nerve fibers with varicosity are densely distributed throughout the duodenal villi. $\times 90$ 

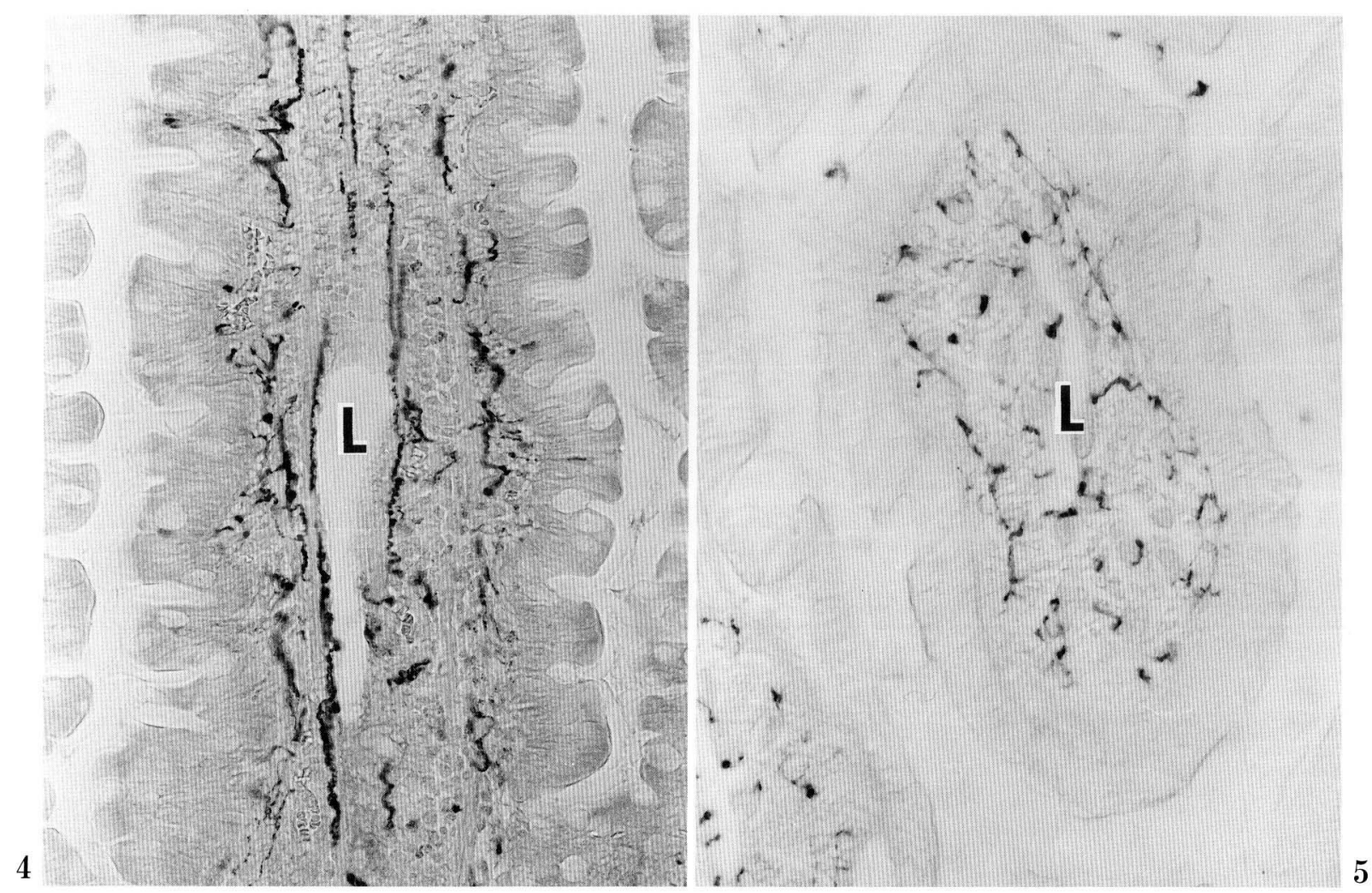

Figs. 4 and 5. The intermediate portion of the duodenal villi is cut perpendicularly (Fig. 4 ) and transversely (Fig. 5). The CGRP-immunoreactive nerves ran along the bundles of smooth muscle, some of them showing the close association with the endothelial cells of the central lacteal. $L$ central lacteal. $\times 180$

SP/CGRP-immunoreactive nerve fibers.

In the proximal portion of the villus, the major population of the SP/CGRP-immunoreactive nerves ran along the fasciculi of smooth muscle fibers which were located closer to the villous axis (Figs. 2, 3).

In the intermediate portion, the SP/CGRP-immunoreactive nerves ran along the bundles of smooth muscle cells and also extended a dense network to the subepithelial regions. Another dense distribution of the nerves, noteworthily, was found around the central lacteal lymphatics (Figs. 4, 5). The lymphaticassociated nerves took a course very close to the endothelial cells of the central lacteal.

In the distal portion of the villus, the SP/CGRP. immunoreactive fibers revealed a dense distribution in the subepithelial region which were rich in capillaries (Fig. 6). Though several immunoreactive nerves still ran along the fasciculi of the smooth muscle fibers, they were seldom seen around the central lacteal.

\section{Immunoelectron microscopy}

The SP or CGRP-immunoreactive nerves were easily identified under the electron microscope, due to the electron-dense reaction products. Only in the intermediate portion of the villus were the nerves found in close association with the endothelium of the central lacteal. Grouped or single immunoreactive nerve fibers were located immediately beneath the endothelial cells of the lacteal lymphatic (Figs. 7-9). The nerve fibers, exposed from their Schwann sheaths, made contact for a long distance with the basal cytoplasm of endothelial cells - partly intercalated by the basement membrane, partly without their intercalation (Figs. 7, 8). The nerve and endothelial cells made contact over a 15-35 nm wide slit, showing no structural specialization of their membranes. Some isolated fibers invaded the cytoplasm of the endothelial cells, often showing profiles of knob-like swellings (Fig. 9).

Immunoreactivies for SP and CGRP were localized 


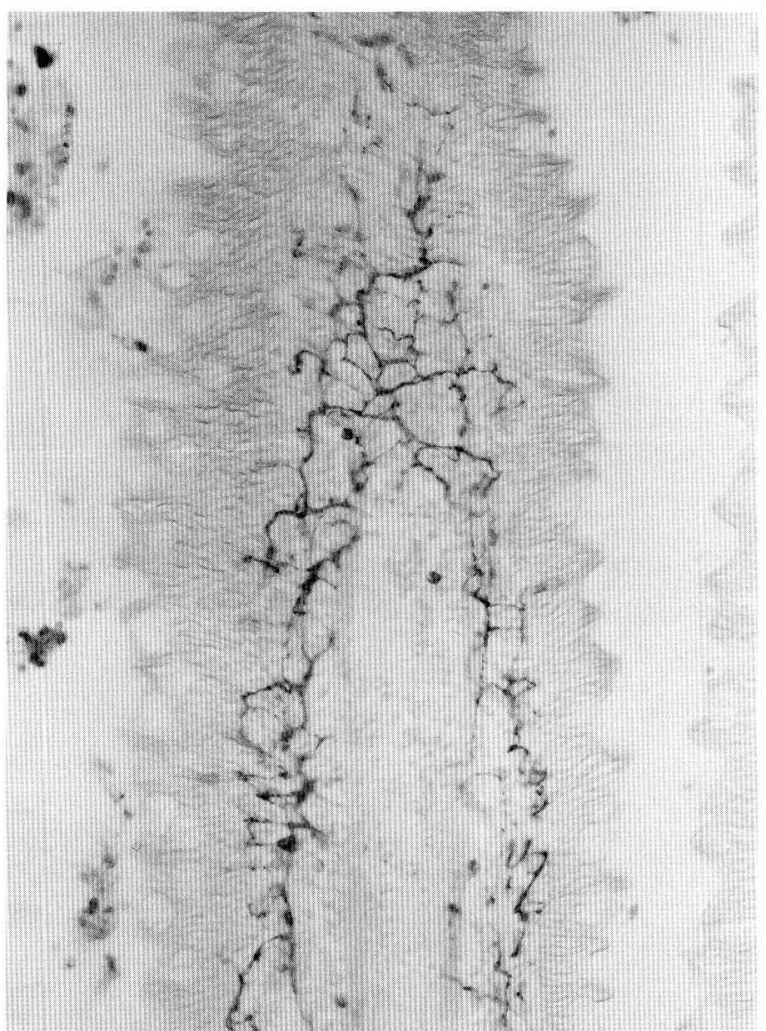

Fig. 6. CGRP-immunoreactive fibers in the distal portion of a duodenal villus. A developed nerve plexus is seen in the subepithelial region. $\times 180$

mainly in large cored vesicles $60-90 \mathrm{~nm}$ in diameter, though part of the axoplasm was spotted with presumed perfusions of immunoreactive substances (Figs. 7-9).

\section{DISCUSSION}

The intestinal villi are known to be rich in nerve fibers which are mainly distributed in the subepithelial region and associated with smooth muscles running along the villous core (FURNESS and CosTA, 1987). Recently, we demonstrated by electron microscopy a hitherto unknown dense innervation in the intestinal villi of the dog: a great number of nerve fibers were found to gather directly on the central lacteal lymphatics (ICHIKAWA et al., 1990). Here, nerve fibers contacted the lymphatic endothelium, with some even penetrating the endothelial cells. We further demonstrated large-cored vesicles in these nerves, suggesting their peptidergic nature.

The present immunohistochemical study indicated that the central lacteal-associated nerves in the dog predominantly contained SP and CGRP, and that these two neuropeptides were localized in identical nerve fibers. As is widely known, SP and CGRP show a general tendency to co-exist throughout the peripheral nervous system (ISHIDA-YAMAMOTO and TOHYAMA, 1989).

The lymphatic vessels of small diameter are generally believed to be lacking in nervous supply. OHHA. SHI et al. $(1982,1983)$ have reported that peptidergic nerves containing VIP and NPY are associated with lymphatic vessels in the bovine mesenterium to regulate their contraction and dilation. However, the materials used by OHHASHI et al. $(1982,1983)$ were large lymphatics with a developed muscular layer which might correspond in construction to that of arterioles.

Since the central lacteals in the intestinal villi of dogs are not equipped with any smooth muscle cells, the lacteal-associated nerves may be not vasomotors, instead being sensory in nature. This idea is supported by the present immunohistochemical demonstration showing that most of the nerve fibers contained SP and CGRP which are, typically, characteristic of primary sensory neurons (GIBSON et al., 1984). These nerve fibers penetrated into the lymphatic endothelial cells as if to be anchored to the cells. It would not seem unreasonable to propose that the endothelium attached with nerves may represent a mechanoreceptive complex, serving for the detection of luminal pressure or endothelial extension. It is, however, worthy to note that a chemoreceptive function for the detection of small molecular substances diffusible from the lacteal lumen through the thin layer of endothelial cytoplasm may not be excluded.

The present immunostaining at the electron microscopic level demonstrated that the immunoreactivities for SP and CGRP were cnoncentrated on the large-cored vesicles, being more amply contained in swollen portions of the lymphatics-associating nerve fibers. Recently, the release of bioactive substances at the distal ends of afferent fibers has attracted attention (MagGi and Meli, 1988). An experimental study demonstrated that a scalding injury to the skin caused an increase in immunoreactive SP levels in the lymph fluid, suggesting the release of SP from the sensory nerve endings into lymphatic vessels (Jons. SON et al., 1986). According to our previous observations, however, the knob-like nerve fibers invaginating into the basal cytoplasm of lymphatic endothelial cells were poor in cell-organellae, including largecored vesicles (ICHIKAWA et al., 1989, 1990). The immunoreactivities for SP/CGRP were found in this study to be considerably low in the portions in- 

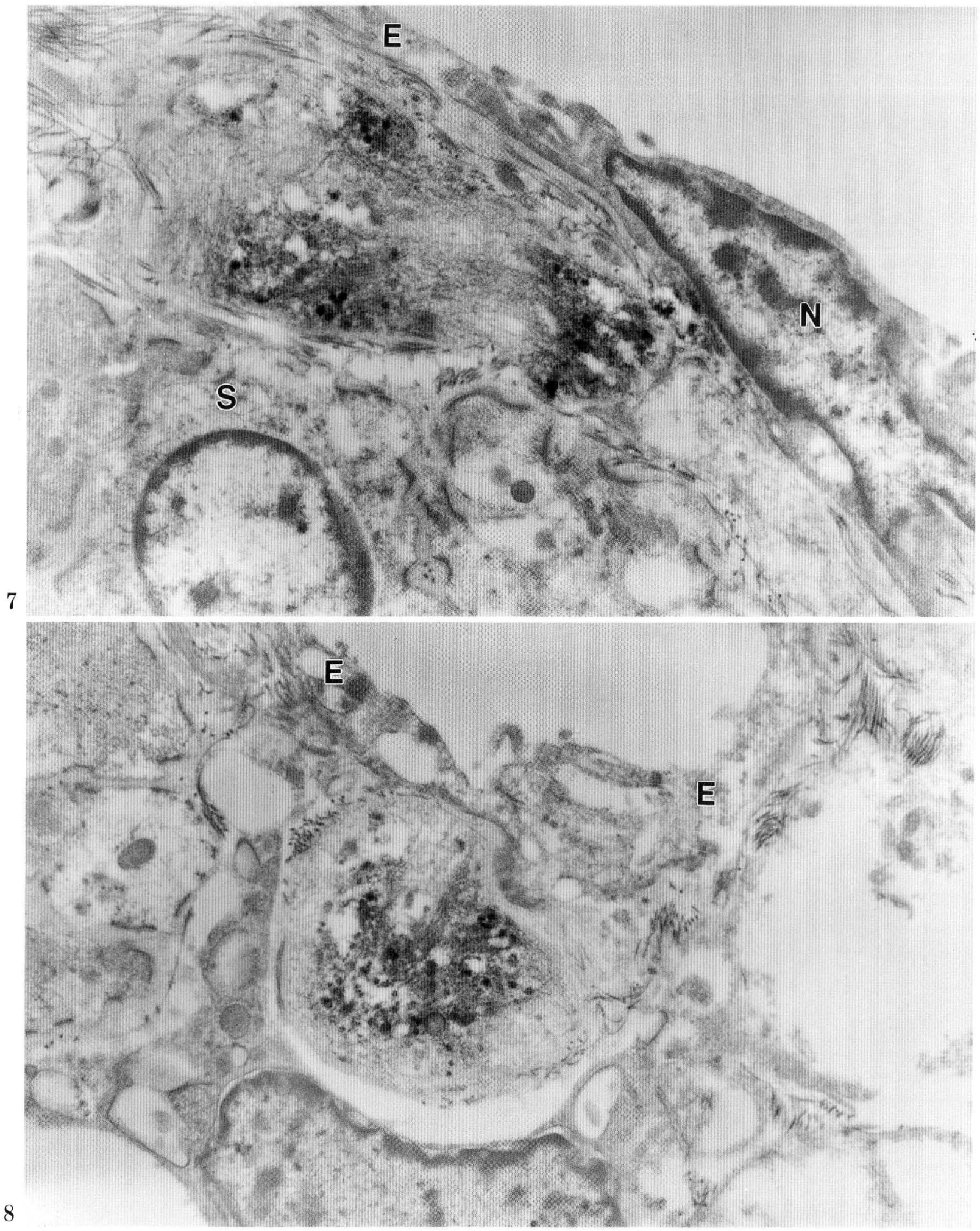

Figs. 7-9. Immunoelectron micrographs showing the topographical relationship of the central lacteal endothelium and CGRP-immunoreactive fibers in the intermediate portion of the villi. The CGRP-immunoreactive nerve fibers are located beneath the endothelium $(E)$ of the lacteal lymphatics, some swollen portions being in contact with the epithelium (Fig. 8). The electron-dense immunoreactivity was observed mainly in large cored vesicles (Figs. 7, 8). In Fig. 9, an immunoreactive nerve element (arrow) penetrates into the cytoplasm of an endothelial cell. $N$ nucleus of endothelial cell, $S$ smooth muscle cells. Fig. 7: $\times 20,000$, Fig. $8: \times 16,000$, Fig. 9: $\times 23,000$ 


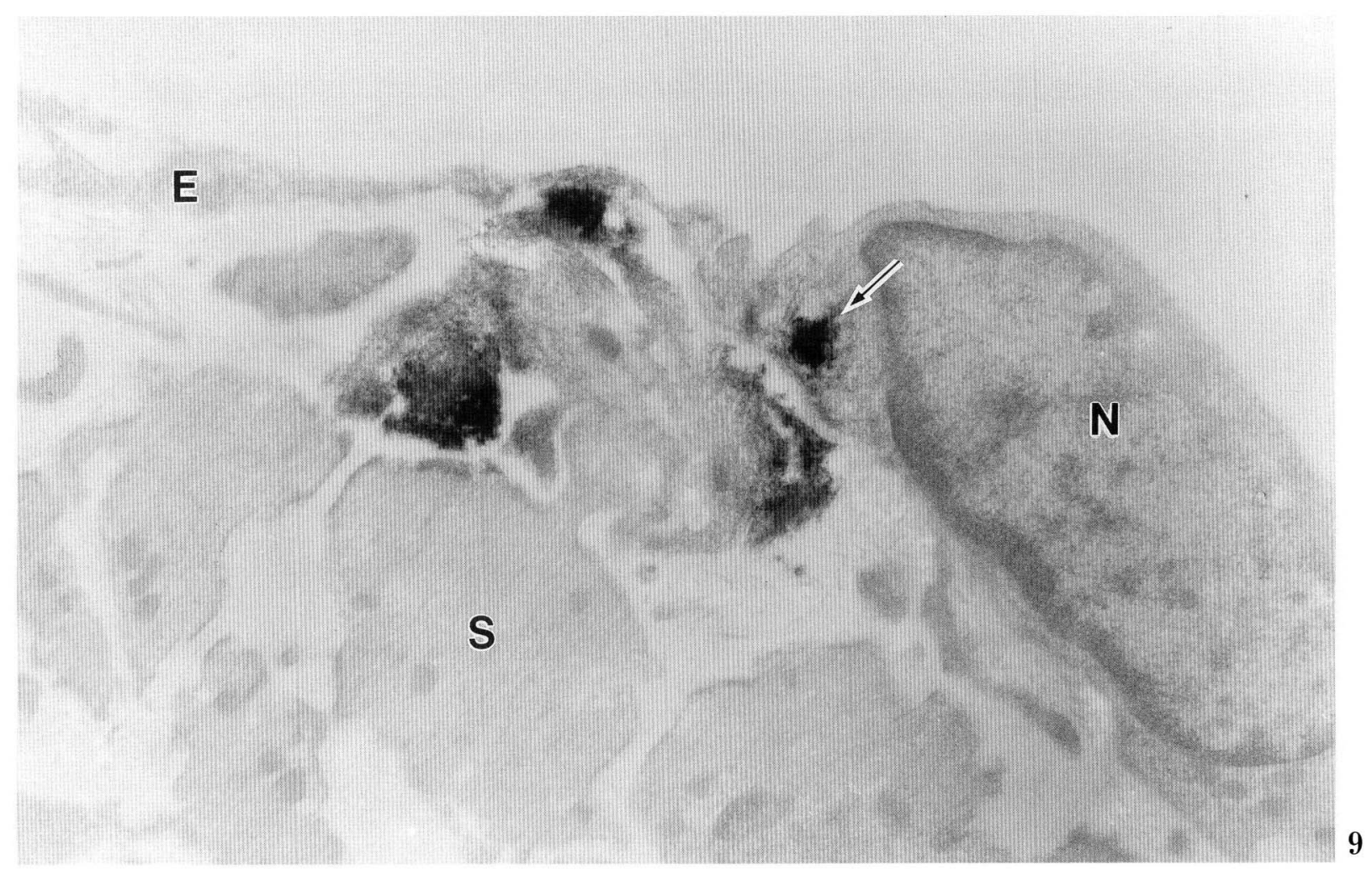

vaginating into the endothelial cells, but high in the nervous portions located outside the endothelium of central lacteals. These findings suggest that SP and CGRP may not be directly released into the lumen of the central lacteals, but secreted against the endothelial cells and/or surrounding cells, especially smooth muscle cells.

Although the functional significance of $\mathrm{SP}$ and CGRP to the intestinal lymphatic system remains to be elucidated, some interesting studies are available. It has been shown that a capsaicin treatment, which is known to deplete SP from primary sensory neurons (JESSELL et al., 1978), reduces oedema formation after scalding (SARIA and LUNDBERG, 1983; SARIA, 1984). It is likely that SP or CGRP in the intestinal villi regulates the intravillous fluid volume by changing the permeability of lymphatic endothelial cells. On the other hand, recent studies have suggested that CGRP and other neuropeptides secreted from sensory nerve terminals induce and activate leucocytes and macrophages (PAYAN et al., 1987; PECK, 1987). Noteworthily, we have observed in the intestinal villi of dogs that numerous lymphocytes and granulocytes are gathered in the central lacteals in which endothelial cells are richly innervated (ICHIKAWA et al., 1989, 1990).
Acknowledgments. The authors are grateful to Dr. Masato OKUBo for technical assistance and helpful discussion, and to Miss. Mieko Nizzuma for her technical assistance.

\section{REFERENCES}

Burnstock, G.: Innervation of smooth muscle. In: (ed. by) E. Bulbring, A. F. Brading, A. W. Jones and T. Tomita: Smooth muscle. Edward Aenold Ltd., London, 1970 (p. 34-56).

Campbell, T. and T. Heath: Intrinsic contractility of lymphatics in sheep and dogs. Quart. J. Exp. Physiol. 58: 207-217 (1973).

Furness, J. B. and M. Costa: Arrangement of the enteric plexuses. In: The enteric nervous system. Churcill Livingstone, 1987 (p. 6-23).

Gibson, S. J., J. M. Polak, S. R. Bloom, I. M. Sabate, P. M. Mulderry, M. A. Ghatei, G. P. McGregor, J. F. B. Morrison, J. S. Kelly, R. M. Evans and M. G. RosenfelD: Calcitonin gene-related peptide immunoreactivity in the spinal cord of man and eight other species. J. Neurosci. 4: 3101-3111 (1984).

HaLl, J. G., B. Morris and G. Wooley: Intrinsic rhythmic propulsion of lymph in the unanesthetized sheep. J. Physiol. 180: 336-349 (1965). 
HöKfelt, T., O. Johansson, A. LJUNGDAHL, J. M. LUNDBERG and M. Schultzberg: Peptidergic neurones. Nature 284: 515-521 (1980).

ICHIKAWA, S., S. UChino and Y. Hirata: Nerve terminals associated with the central lacteal endothelial cells. Okajimas Fol. Anat. Jap. 66: 57-60 (1989).

ICHIKAWa, S., M. OKubo, S. Uchino and Y. Hirata: The intimate association of nerve terminals with the lacteal endothelium in the canine duodenal villi observed by transmission electron microscopy of serial sections. Arch. Histol. Cytol. 53, Suppl.: 137-146 (1990).

Ishida-Yamamoto, A. and M. Tohyama: Calcitonin generelated peptide in the nervous tissue. Progr. Neurobiol. 33: 335-386 (1989).

Jessel, T., L. L. Iverssen and A. C. Cuello: Capsaicininduced depletion of substance $\mathrm{P}$ from primary sensory neurons. Brain Res. 152: 183-188 (1978).

Jonsson, C. E., E. Brodin, C. J. Dalsgaard and A. HaEgerstrand: Release of substance-P-like immunoreactivity in dog paw lymph after scalding injury. Acta Physiol. Scand. 126: 21-24 (1968).

MAGGi, C. A. and A. Meli: The sensory-efferent function of capsaicin-sensitive sensory neurons. Gen. Pharmacol. 19: 1-43 (1988).

Mchale, N. G., I. C. Poddie and K. D. Thornbury : Nervous modulation of spontaneous contractions in bovine messenteric lymphatics. J. Physiol. 309: 461-467 (1980).

NiHEI, K. and T. IwANAGA: Localization of Met-enkephalinArg-Gly-Leu-like immunoreactivity in the gastrointestinal tract of rat and pig. J. Histochem. Cytochem. 33: 1001-1006 (1985).

Ohнashi, AT., S. Kobayashi, S. Tsukahara and T. Azuma: Innervation of bovine mesenteric lymphatics: From the histochemical point of view. Microvascul. Res. 24: 377-385 (1982).

Оhнashi, T., J. A. Olschowka and D. M. Jacobowitz: Vasoactive intestinal peptide inhibitory innervation in bovine mesenteric lymphatics - A histochemical and pharmacological study. Circulation Res. 53: 535-538 (1983).
Payan, D. G., J. P. McGillis, F. K. Renold, M. MitsuHASHI and E. J. GoETzL: Neuropeptide modulation of leukocyte function. New York Acad. Sci. 496: 182-191 (1987).

Peck, R.: Neuropeptides modulating macrophage function. Ann. New York Acad. Sci. 496: 264-270 (1987).

SARIA, A.: Substance P in sensory nerve fibers contributes to the development of oedema in the rat hind paw after thermal injury. Brit. J. Pharmacol. 82: 217-222 (1984).

Saria, A. and J. M. Lundberg: Capsaicin pretreatment inhibits heat-induced oedema in rat skin. Naunyn Schmiedebergs Arch. Exp. Pathol. Pharmakol. 323: 341-342 (1983).

Yanaihara, N., M. Sakagani, H. Sato, K. Yamamoto, T. Hashimoto, C. Yanaihara, Z. Ito, K. Yamaguchi and K. ABE: Immunological aspect of secretin, substance P, and VIP. Gastroenterology 72: 803-810 (1977).

Yanaihara, N., C. Yanaihara, T. Mochizuki, K. IWa haRA, T. FuJita and T. Iwanaga: Immunoreactive GRP. Peptides 2, Suppl.: 185-191 (1981).

Dr. Sanae ICHIKAWA

Department of Anatomy

Tokyo Medical College

6-1-1 Shinjuku, Shinjuku-ku

Tokyo, 160 Japan

市川早苗

160 東京都新宿区新宿 6 丁目 1 - 1

東京医科大学

第一解剖学教室 